\title{
An analysis of reported cases of leishmaniasis in the southern Ecuadorian Amazon region, 1986-2012
}

\author{
Hector R. Olalla a , Lenin N. Velez ${ }^{\mathrm{b}, \mathrm{c}}$, Hirotomo Kato ${ }^{\mathrm{d}}$, Kazue Hashiguchi ${ }^{\mathrm{e}}$, \\ Abraham G. Caceres ${ }^{f, g}$, Eduardo A. Gomez ${ }^{b, c}$, Flavio C. Zambranoc ${ }^{c}$, \\ Daniel A. Romero-Álvarez ${ }^{\mathrm{e}}$, Angel G. Guevara ${ }^{\mathrm{e}}$, Yoshihisa Hashiguchi ${ }^{\mathrm{e}, \mathrm{h}, \mathrm{i}, *}$ \\ a Hospital Zumba, Zumba, Cantón Chinchipe, Zamora-Chinchipe, Ecuador \\ b Departamento de Medicina Tropical, Facultad de Medicina, Universidad Católica de Guayaquil, Guayaquil, Ecuador \\ c Servicio Nacional de Erradicación de la Malaria (SNEM), Guayaquil, Ecuador \\ d Laboratory of Parasitology, Department of Disease Control, Graduate School of Veterinary Medicine, Hokkaido University, Sapporo, Hokkaido, Japan \\ e Centro de Biomedicina, Facultad de Ciencias Médicas, Universidad Central del Ecuador, Quito, Ecuador \\ ${ }^{\mathrm{f}}$ Departamento Académico de Microbiología Médica, Facultad de Medicina Humana, Universidad Nacional Mayor de San Marcos, Lima, Peru \\ I Instituto Nacional de Salud (INS), Lima, Peru \\ h Proyecto-Prometeo, Secretaría Nacional de Educación Superior, Ciencia, Tecnología e Innovación (SENESCYT), Quito, Ecuador \\ i Department of Parasitology, Kochi Medical School, Kochi University, Kochi, Japan
}

\section{A R T I C L E I N F O}

\section{Article history:}

Received 31 December 2014

Received in revised form 7 March 2015

Accepted 10 March 2015

Available online 18 March 2015

\section{Keywords:}

Cutaneous leishmaniasis

Retrospective analysis

Reported cases

Southern Ecuadorian Amazon region

\begin{abstract}
A B S T R A C T
An analysis of reported cases of cutaneous leishmaniasis (CL) was performed using the data registered in the southern Ecuadorian Amazon region during 27 years from 1986 to 2012. The cases/subjects with both the suspected CL lesions and the amastigote-positive results were recruited for the analysis. The yearly occurrence of cases showed a markedly higher number during the six years, 1988 and 1993. After 1994 when the insecticide spraying campaign using helicopter in 1993-1994, the number dropped remarkably. Then, the yearly occurrence gradually fluctuated from 101 cases in 1996 to 11 in 2009, maintaining a low number of cases after the campaign. The monthly occurrence of cases showed a markedly high number during March and August, suggesting a correlation to the rainy season (months) in the areas. A statistical significance was found between the monthly average number of the CL case and the average precipitation $(p=0.01474)$. It was suggested that the time of transmission of CL would depend on the rainy seasons at each endemic area of Ecuador, which has a diverse climatic feature depending on the geographic regions. Such information at given leishmaniasis-endemic areas of Ecuador would be important for the future planning of the disease control. Molecular analysis and characterization of clinical samples revealed the presence of Leishmania (Viannia) braziliensis.
\end{abstract}

(c) 2015 Elsevier B.V. All rights reserved.

\section{Introduction}

Leishmaniasis is caused by a protozoan parasite of the genus Leishmania, and transmitted by a sand fly of the genera Phlebotomus and Lutzomyia in the Old and New World, respectively. A total of about 20 species of Leishmania parasites in the world are responsible for a wide range of clinical manifestations. Cutaneous leishmaniasis (CL) ranges from simple types to those producing destructive mucocutaneous leishmaniasis (MCL) and non-healing diffuse cutaneous leishmaniasis (DCL). Visceral leishmaniasis (VL) is the severe

\footnotetext{
* Corresponding author at: Centro de Biomedicna, Facultad de Ciencias Médicas, Universidad Central del Ecuador, Sodiro N-14121 e Iquique, Ciudad de Quito, Pichincha, Ecuador. Tel.: +59302 3228455; fax: +593023228455.

E-mail address: yhashiguchi42@yahoo.co.jp (Y. Hashiguchi).
}

chronic infection, which is often fatal if left untreated. These different types of the disease are endemic in many tropical and subtropical regions in the world with two million annual incidence and 350 million people at risk (Desjeux, 2001; Alvar et al., 2012).

In the New World, leishmaniases are endemic in Central and South American countries, including southern parts of the US (Grimaldi et al., 1989). Control of the disease in the New World is complicated by the variety of different Leishmania species and their diverse clinical forms, and also complicated by unique epidemiological patterns of each Leishmania species. Furthermore, in many regions of the New World, two or more Leishmania species are often sympatric. In Ecuador, seven species of the genus Leishmania, Leishmania (Viannia) braziliensis, L. (V.) panamensis, L. (V.) guyanensis, L. (V.) naiffi, Leishmania (Leishmania) mexicana, L. (L.) amazonensis, and L. (L.) major-like are reported (Mimori et al., 1989; Armijos et al., 1990; Hashiguchi and Gomez, 1991; Hashiguchi et al., 
1991; Furuya et al., 1997; Calvopiña et al., 2004; Kato et al., 2008, 2013; Gomez et al., 2014a,b). The CL is the most frequent clinical feature of the disease in the country, but MCL cases are also seen (Hashiguchi and Gomez, 1991; Calvopiña et al., 2004). The first case of CL in Ecuador was reported by Valenzuela in 1920 in Esmeraldas province, close to the border of Colombia, and MCL case was first described in 1924 by Heinert (Rodriguez, 1974). Since then, many clinical cases of CL and MCL have been reported in the country. Most of the clinical cases of leishmaniasis in Ecuador were reported from the Pacific coastal region (Heinert, 1924; Leon, 1951; Carrera, 1953; Rodriguez and Aviles, 1953; Rodriguez, 1974; Calero and Coronel, 1981; Hashiguchi et al., 1984; Mimori et al., 1989; Armijos et al., 1990; Hashiguchi and Gomez, 1991; Hashiguchi et al., 1991; Furuya et al., 1997; Calvopiña et al., 2004), with very few numbers from the Amazonian regions (Amunarriz, 1982; Hashiguchi and Gomez, 1991; Calvopiña et al., 2004; Kato et al., 2008, 2013) where communications and the medical care system are generally inadequate. Cases of CL have also been reported from the Andean region (Hashiguchi et al., 1991; Gomez et al., 2014a,b). Still, the lack of a well structured information system has not allowed the elaboration of a good and representative epidemiological feature of the disease, requiring more information at given endemic areas of the country.

In this study, we performed an analysis of leishmaniasis cases reported in the southern Ecuadorian Amazon region during 27 years from 1986 to 2012. The yearly and monthly occurrence of the CL cases was analyzed, in relation to the climate changes especially precipitation, insecticide spraying campaign and other factors, such as human life styles, deforestation and migration. Furthermore, to obtain information on the causative Leishmania species circulating in the areas, molecular analysis and characterization of clinical samples were made.

\section{Materials and methods}

\subsection{Study sites}

Zamora-Chinchipe province is composed of nine cantons/regions in the southeast of Ecuador, and Palanda and Chinchipe are located in the southernmost of the province. The present study sites (Fig. 1), canton Chinchipe (4 $51^{\prime} 46^{\prime \prime} \mathrm{S}$ latitude, $79^{\circ} 07^{\prime} 58^{\prime \prime} \mathrm{W}$ longitude; $1113-1200 \mathrm{~m}$ a.s.l., $1207 \mathrm{~km}^{2}$, av. temp. $21-22^{\circ} \mathrm{C}$ ) with 9119 inhabitants in 2010 and canton Palanda ( $4^{\circ} 38^{\prime} 59^{\prime \prime} \mathrm{S}$ latitude, $79^{\circ} 07^{\prime} 56^{\prime \prime} \mathrm{W}$ longitude; $1020-1735 \mathrm{~m}$ a.s.l., $1986 \mathrm{~km}^{2}$, av. temp. $20-22^{\circ} \mathrm{C}$ ) with 8089 inhabitants in 2010 , belong to Zamora-Chinchipe province $(815-2800 \mathrm{~m}$ a.s.l.; precipitation, $2000 \mathrm{~mm} / \mathrm{year}$; av. temp. $17-22^{\circ} \mathrm{C}$; relative humidity, >99\%; humidity index, 92\%; Plan de Desarrollo y Ordenamiento Territorial, Unidad de Gestion Territorial Zamora-Chinchipe, http://www.zamora-chinchipe.gob.ec) at the southern Ecuadorian Amazon region. Fig. 2 shows panoramic features of study sites, Palanda and Chinchipe (Ishimanchi), located in forested and mountainous areas. Inhabitants of the areas work mostly in agriculture at the field surrounded by primary or secondary forests, except those engaging in commercial activities in the urban areas of parish Zumba and Palanda. Population migration from rural areas to urban areas was found from the past to date and the construction of new roads has been progressed in the regions (see Fig. 2).

\subsection{Subjects}

The subjects recorded had come from different endemic foci within canton Chinchipe and Palanda, Zamora-Chinchipe province. All the subjects received differential diagnosis of leishmaniasis at the laboratories of outpatient facilities of the Zumba hospital (Chinchipe) and Palanda health center. One of the main activities of the laboratories of these medical/health institutions is to provide differential diagnosis of various parasitological, bacterial, viral and fungal infections in the areas. Thus, the subjects with suspected $\mathrm{CL}$ lesions came from almost all the endemic areas of the Canton Chinchipe and Palanda. Questionnaires were prepared to record the residence and occupation of the patients, the evolution and history of the disease, and information on the treatment and others. More than $95 \%$ of the study participants lived on farms located at dense forested and mountainous areas. In this study, only the clinical cases with both the suspected CL lesions and the amastigote (smear) positive results were recruited for the analysis, but those without demonstrating the parasites in the smears were excluded unless otherwise specified. Thus, a total of parasitologically confirmed $2323 \mathrm{CL}$ cases registered at the laboratories between 1986 and 2012 were analyzed. Apart from these retrospective studies,

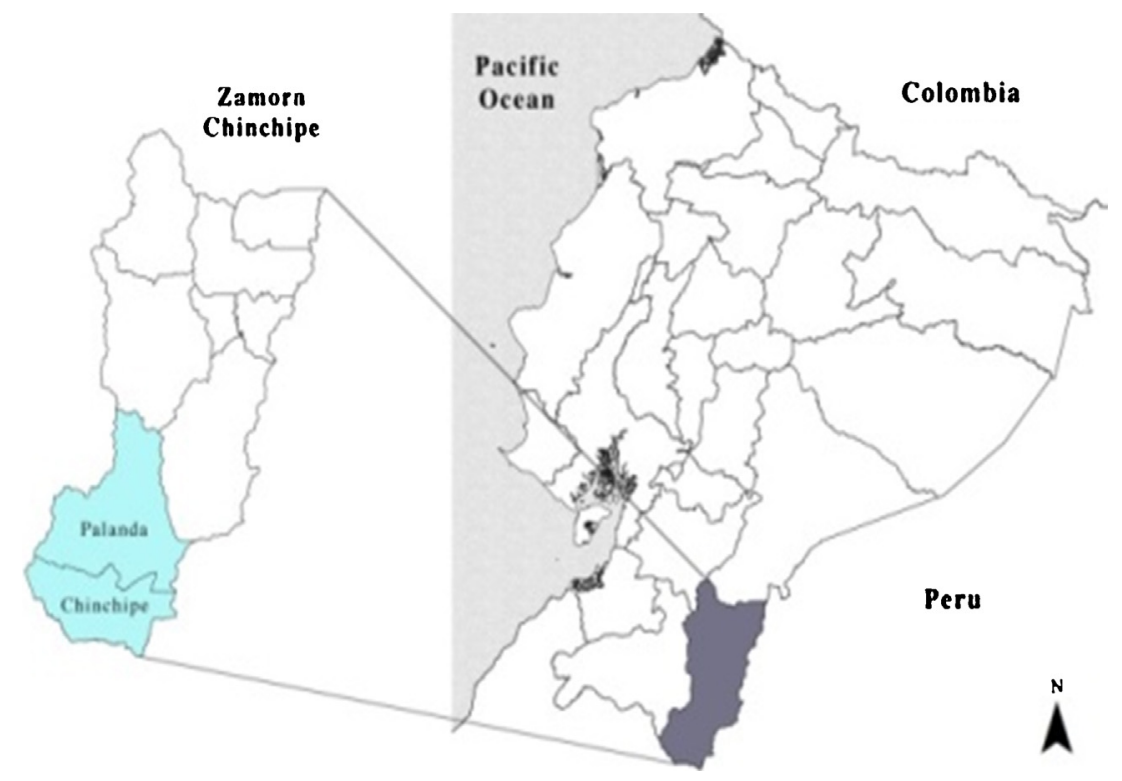

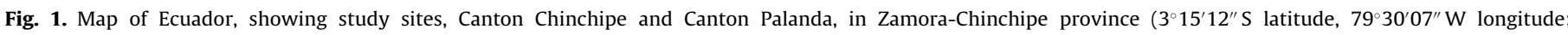
http://www.zamora-chinchipe.gob.ec). 


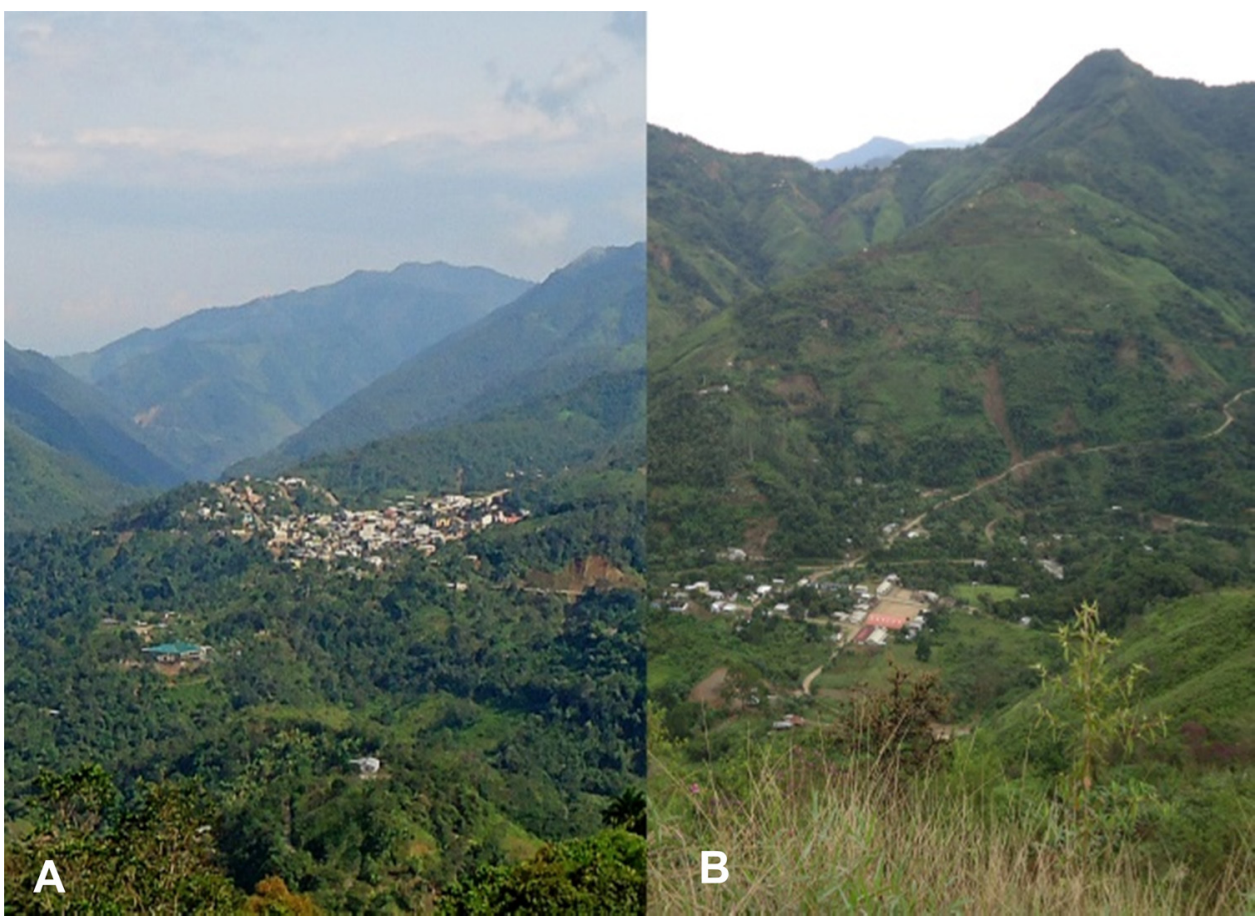

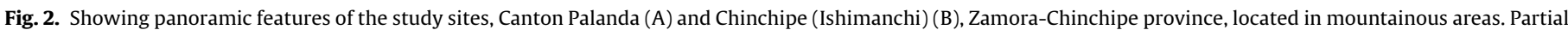

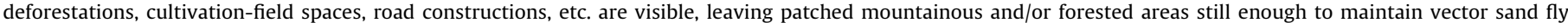
breeding sites.

clinical samples from CL patients were collected, and molecular characterization was performed for the identification of parasite species of the genus Leishmania circulating in the areas. Informed consent was obtained from the subjects that participated in the study.

\subsection{Microscopic examinations}

Materials were taken from the margin of ulcerous (Fig. 3) and/or nodular lesions using a surgical knife by experienced technicians, and then smeared onto a slide glass to make a thin film. After

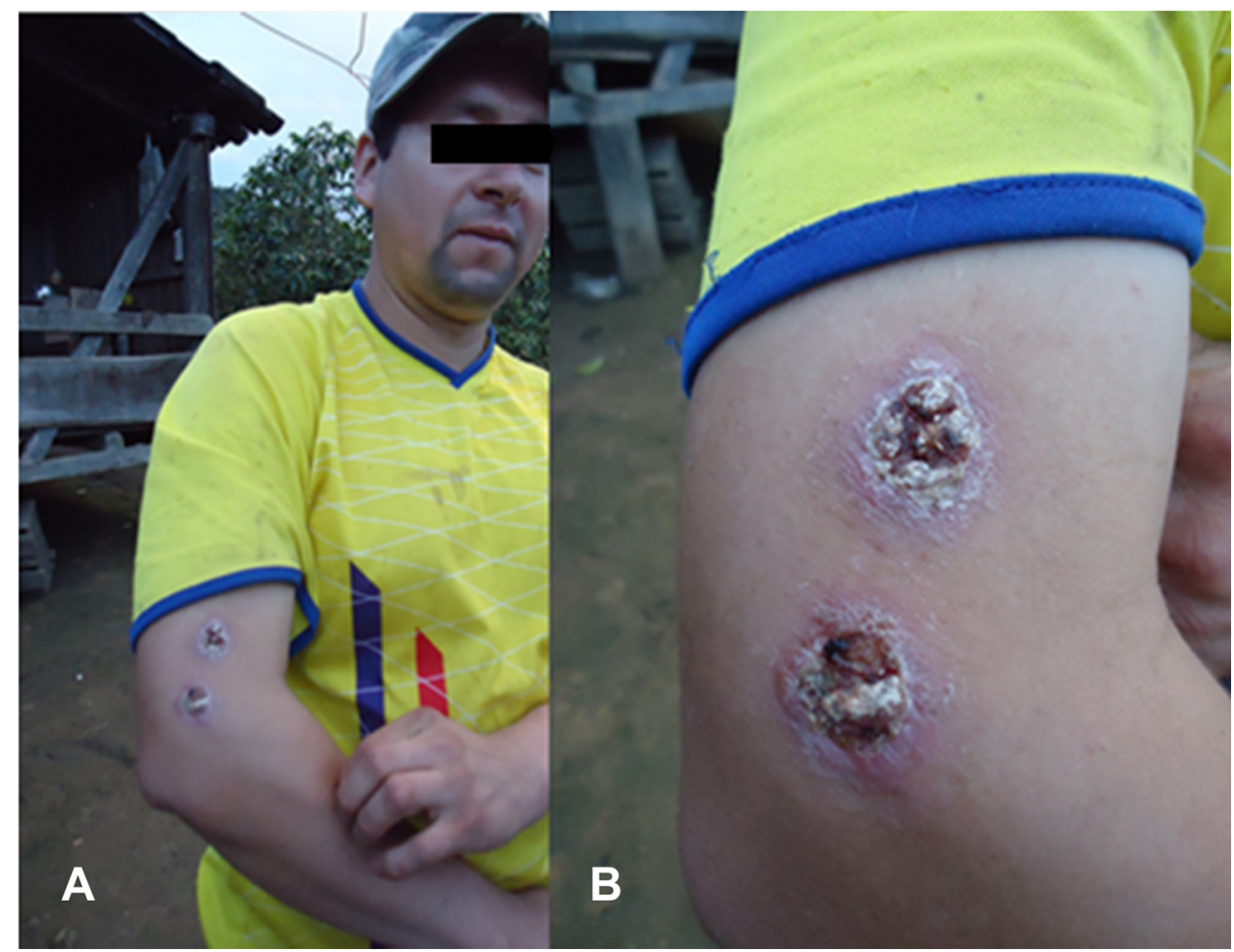

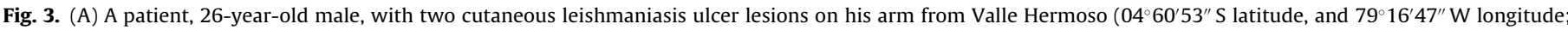
$1712 \mathrm{~m}$ a.s.l.), Palanda, Zamora-Chinchipe province, Ecuador. (B) Magnified view of the two ulcer lesions. 
drying the materials at room temperature, they were stained with Giemsa and then examined for the amastigotes under a microscope at magnifications of $400 \times$ and/or $1000 \times$.

\subsection{Meteorological data}

In the present study sites (Chinchipe and Palanda), no meteorological station was available. Therefore, the meteorological data employed here were derived from the most closely situated station to the study sites: M503 San Francisco San Roman - INAMHI, Zamora-Chinchipe (Instituto Nacional de Meteorologia e Hidrologia; http://www.inamhi.gob.ec) located at $03^{\circ} 57^{\prime} 50^{\prime \prime}$ S latitude, and $79^{\circ} 04^{\prime} 19^{\prime \prime}$ W longitude; $1620 \mathrm{~m}$ a.s.l.). Still, however, in this station only the data of precipitation were available and no other data such as maximum and minimum temperatures and humidity were recorded. Furthermore, the complete data of monthly precipitation were available after 1990 onwards.

\subsection{Clinical samples from patients for PCR analysis}

Clinical samples for PCR analysis were taken by scraping the margin of active lesions of the patients, spotted onto a FTA Classic Card (Whatman, Newton Center, MA) and stored at room temperature. Disks $2 \mathrm{~mm}$ in diameter were punched out from each filter paper and washed three times with FTA purification Reagent (Whatman) and once with Tris-EDTA buffer. The disks were airdried and directly subjected to PCR amplification. Nested PCR was performed to amplify the Leishmania cytochrome b (cyt b) gene from a patient specimen collected on the FTA Cards. Primers used for nested PCR were L.cyt-AS (5'-GCGGAGAGRARGAAAAGGC-3') and L.cyt-AR (5'-CCACTCATAAATATACTATA-3') for the first PCR, and L.cyt-S and L.cyt-R for the second PCR (Kato et al., 2008, 2013). Materials from smear specimens on the slide glass were also processed to the PCR analysis.

\subsection{Phylogenetic analysis}

Cyt b gene sequences were aligned with CLUSTAL W software (Thompson et al., 1994) and examined using the program MEGA (Molecular Evolutionary Genetics Analysis) version 5.1 (Tamura et al., 2011). Phylogenetic trees were constructed by the neighborjoining method with the distance algorithms available in the MEGA package. Bootstrap values were determined with 1000 replicates of the data sets. The database for phylogenetic analyses consisted of cyt $\mathrm{b}$ gene sequences from Gen Banks of 12 Leishmania species, viz., L. (V.) braziliensis, L. (V.) guyanensis, L. (V.) panamensis, L. (V.) shawi, L. (V.) naiffi, L. (V.) lainsoni, L. (L.) mexicana, L. (L.) amazonensis, L. (L.) major, $L$. (L.) tropica, $L$. (L.) donovani, and $L$. (L.) infantum.

\subsection{Statistical analysis}

For the statistical analysis, a linear regression analysis was employed using the package Statplus of Microsoft Excel 2011 and RStudio software for Macintosh 10 OSX operating system. Correlation between the variables, monthly reported CL cases and monthly precipitation (in $\mathrm{mm}$ ), was determined by the correlation coefficient $(R)$ and the coefficient of determination $\left(R^{2}\right)$ considering a $95 \%$ of confidence for the statistical significance. For the normality assumption of the variables, the Shapiro-Wilk test was used. The analysis was performed within four years between 1990 and 1993 for the following two reasons: no data were available at the meteorological station (M503-INAMHI) before 1990; and the dropping of CL cases after 1994 following the insecticide spraying campaign; the low numbers of cases were not sufficiently enough for considering a further analysis thereafter. The total data were analyzed and also the variables by individual year and the average of both variables per month.

\section{Results}

\subsection{Yearly occurrence of reported cases}

Between 1986 and 2012 (27 years), a total of 2323 Leishmania positive subjects with CL lesions were recorded monthly and arranged by year (Table 1 ). The total number of reported CL cases per year ranged remarkably from 11 (2009) to 405 (1992). The majority of reported cases were found in the six years from 1988 to 1993 , showing a rate of $57.9 \%$ (1324) of the total in the period. A markedly low number of cases per year were recorded after the year 1994 through 2012, except 107 in 1996, 94 in 2004 and 86 in 2011.

\subsection{Monthly occurrence of reported cases}

A marked monthly fluctuation of reported CL cases was recognized during the period from 1986 to 2012, as shown in Table 1. Total monthly numbers in the table had a tendency to show higher rates during March and August (231 in July - 317 in March), suggesting a higher intensity of transmission and/or infection in the period. In the present study, climatic data (only precipitation) were available after 1990 through 2011 at the meteorological station (M503-INAMHI). The data were collaborated to the fluctuation of reported CL cases. For a further precise comparison, the CL case numbers reported during 1990 and 1993 were detected, in which $45.1 \%(1047 / 2323)$ of the total were reported. Again, the majority of reported cases were found in the period from March to August, suggesting a correlation to the rainy season in the present study areas.

\subsubsection{Analysis of relationship between reported cases and precipitation}

When the CL case data (1990-1993) were collaborated to the monthly precipitation (in $\mathrm{mm}$ ), a relationship was suggested. In comparison with the precipitation variable, the CL cases did not follow a normal distribution. For this reason, the rate was corrected applying a logarithm to all the elements of the variable. After the correction, scatterplot graphic with the linear regression line tendency was used to obtain the $R$ and $R^{2}$ values for statistical correlation. The values showed a relationship between the variables, but not significant $(p=0.11822)$. Both the variables in the yearly datasets achieved a normal distribution in all cases. No significant statistical relationship was found between the variables in the four independent associations. Monthly average number of the CL cases and monthly average precipitation were depicted in Fig. 4. The average numbers of both variables obtained in each month from the values of each year were analyzed. The precipitation did not follow a normal distribution, and it was therefore corrected applying a logarithm to all the elements of the variable. A statistical significance between the variables was found, after obtaining the tendency line, the $R$ and $R^{2}(p=0.01474)$.

\subsection{Clinical forms and localization of the lesions}

To obtain information on the clinical forms and localization of the lesions in reported cases, parasitologically confirmed 54 subjects, 30 males, 21.8 (6-89) ages; 24 females, 26.5 (1-71) ages, reported in 2010 were analyzed. The test revealed $94.4 \%$ cutaneous; $3.7 \%$ cutaneous and mucous (mixed); and 1.9\% mucous lesions. No other disease forms of leishmaniasis lesions, such as MCL and DCL were observed. Furthermore, during the study period (1986-2012), no these two forms were found in the areas (Communication: the 
Table 1

Reported cases of leishmaniasis registered at Zumba hospital and Palanda health center, Zamora Chinchipe province, Ecuador, during 1986 and 2012.

\begin{tabular}{|c|c|c|c|c|c|c|c|c|c|c|c|c|c|}
\hline \multirow[t]{2}{*}{ Year } & \multicolumn{12}{|c|}{ Month } & \multirow[t]{2}{*}{ Total } \\
\hline & 1 & 2 & 3 & 4 & 5 & 6 & 7 & 8 & 9 & 10 & 11 & 12 & \\
\hline 1986 & 0 & 6 & 11 & 10 & 7 & 12 & 9 & 12 & 4 & 3 & 2 & 5 & 81 \\
\hline 1987 & 2 & 2 & 5 & 21 & 5 & 7 & 2 & 1 & 1 & 1 & 0 & 0 & 47 \\
\hline 1988 & 2 & 0 & 43 & 8 & 30 & 11 & 17 & 12 & 6 & 4 & 3 & 0 & 136 \\
\hline 1989 & 6 & 13 & 19 & 16 & 11 & 21 & 10 & 9 & 7 & 12 & 6 & 11 & 141 \\
\hline 1990 & 8 & 16 & 19 & 22 & 7 & 12 & 15 & 22 & 10 & 6 & 8 & 10 & 155 \\
\hline 1991 & 19 & 9 & 19 & 20 & 27 & 28 & 20 & 43 & 17 & 13 & 9 & 19 & 243 \\
\hline 1992 & 12 & 19 & 29 & 85 & 45 & 38 & 68 & 51 & 8 & 21 & 18 & 12 & 406 \\
\hline 1993 & 16 & 22 & 48 & 31 & 26 & 33 & 15 & 21 & 9 & 10 & 10 & 3 & 244 \\
\hline 1994 & 9 & 6 & 10 & 17 & 7 & 5 & 4 & 1 & 9 & 4 & 1 & 4 & 77 \\
\hline 1995 & 6 & 3 & 4 & 6 & 6 & 2 & 5 & 12 & 2 & 4 & 5 & 10 & 65 \\
\hline 1996 & 28 & 2 & 19 & 12 & 8 & 14 & 9 & 4 & 2 & 2 & 4 & 3 & 107 \\
\hline 1998 & 9 & 6 & 5 & 3 & 0 & 3 & 0 & 1 & 1 & 0 & 1 & 1 & 30 \\
\hline 1999 & 1 & 3 & 4 & 4 & 4 & 4 & 1 & 3 & 3 & 0 & 0 & 2 & 29 \\
\hline 2000 & 1 & 2 & 1 & 10 & 4 & 3 & 5 & 3 & 1 & 1 & 2 & 0 & 33 \\
\hline 2001 & 1 & 3 & 10 & 4 & 3 & 0 & 5 & 3 & 0 & 1 & 0 & 0 & 30 \\
\hline 2002 & 9 & 4 & 1 & 0 & 0 & 5 & 3 & 8 & 3 & 2 & 4 & 8 & 47 \\
\hline 2003 & 24 & 8 & 5 & 6 & 6 & 2 & 0 & 0 & 0 & 0 & 0 & 0 & 51 \\
\hline 2004 & 4 & 8 & 13 & 7 & 10 & 8 & 16 & 15 & 6 & 4 & 3 & 0 & 94 \\
\hline 2005 & 2 & 3 & 1 & 2 & 5 & 7 & 3 & 8 & 2 & 1 & 2 & 9 & 45 \\
\hline 2006 & 5 & 3 & 5 & 9 & 3 & 5 & 8 & 4 & 6 & 3 & 1 & 0 & 52 \\
\hline 2007 & 0 & 2 & 5 & 4 & 1 & 2 & 1 & 0 & 2 & 1 & 2 & 0 & 20 \\
\hline 2008 & 3 & 6 & 3 & 1 & 2 & 3 & 0 & 1 & 0 & 0 & 0 & 0 & 19 \\
\hline 2009 & 1 & 0 & 1 & 2 & 1 & 0 & 3 & 1 & 0 & 0 & 1 & 1 & 11 \\
\hline 2010 & 2 & 3 & 2 & 4 & 2 & 4 & 3 & 4 & 9 & 10 & 6 & 5 & 54 \\
\hline 2011 & 6 & 5 & 9 & 6 & 12 & 12 & 8 & 6 & 11 & 1 & 5 & 5 & 86 \\
\hline 2012 & 1 & 1 & 5 & 7 & 0 & 1 & 1 & 1 & 1 & 2 & 0 & 1 & 21 \\
\hline Total & 177 & 155 & 296 & 317 & 232 & 242 & 231 & 246 & 120 & 106 & 93 & 109 & 2323 \\
\hline
\end{tabular}

Note: No data are available in 1997, because of logistic, administrative and political reasons of the regional medical institutions in the areas.

first author H.R.O . epidemiologist in the area). The lesions recorded were localized on the face (17.9\%), nose (5.4\%), ear (1.7\%), neck (3.6\%), shoulder (1.7\%), trunk (3.6\%), buttock (3.6\%), upper extremities (42.9\%), and lower extremities (19.6\%). The upper parts of the body surface, face, nose, ear, neck and upper extremities, revealed $71.5 \%$ of the total lesions, suggesting the preferred biting sites of sand fly species of the genus Lutzomyia spp., circulating in the areas.

\subsection{Identification and characterization of Leishmania species}

FTA card samples were obtained from five patients, three from Zumba and two from Palanda, showed positive PCR tests, and one smear specimen (slide-glass) from Zumba revealed positive for the PCR test. All the parasites tested were identified as $L$. (V.) braziliensis, as shown in Fig. 5.

\section{Discussion}

Between 1986 and 2012, a total of 2323 subjects, who visited Zumba hospital and Palanda health center, revealed a positive diagnosis for Leishmania amastigotes in smear specimens. The total numbers shown here are considered to be rather lower than the actual rates of infection, since impression smears alone had been employed in this study as a diagnostic tool. The microscopic

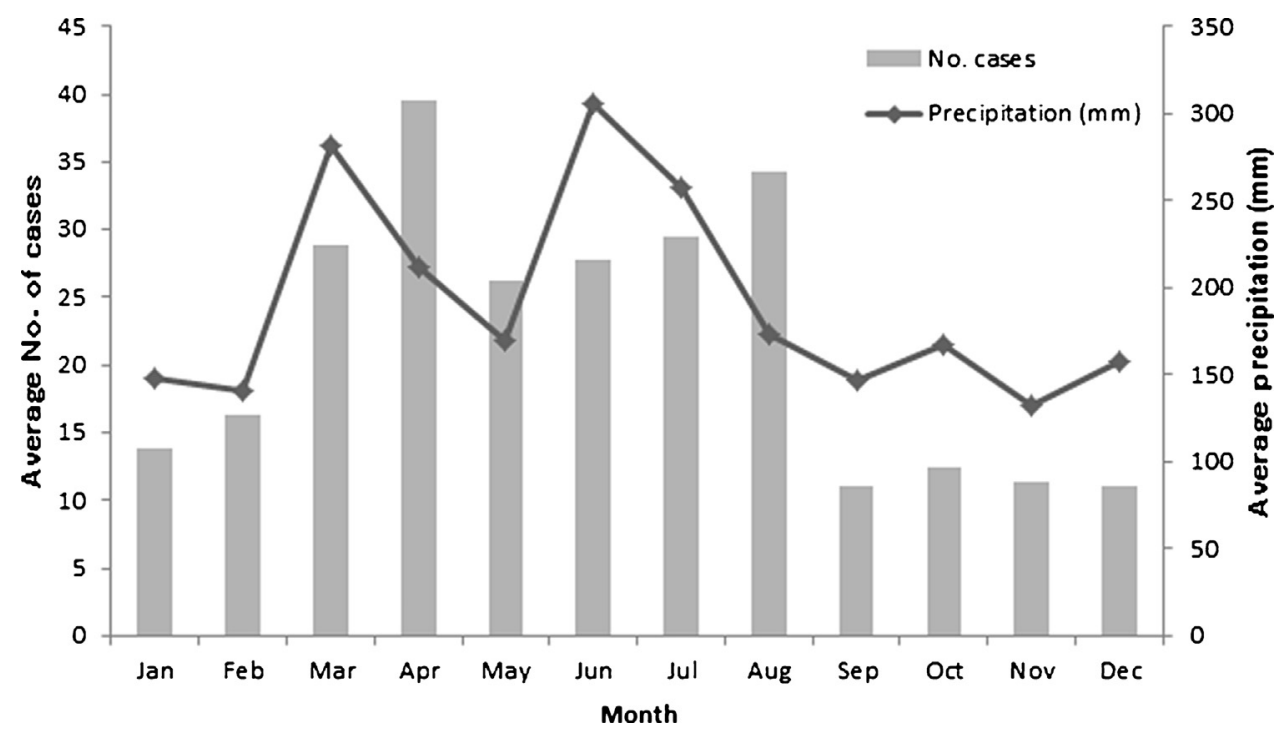

Fig. 4. Relationship between the monthly average number of CL cases and the monthly average precipitation (in mm) during the period of 4 years from 1990 to 1993 . 


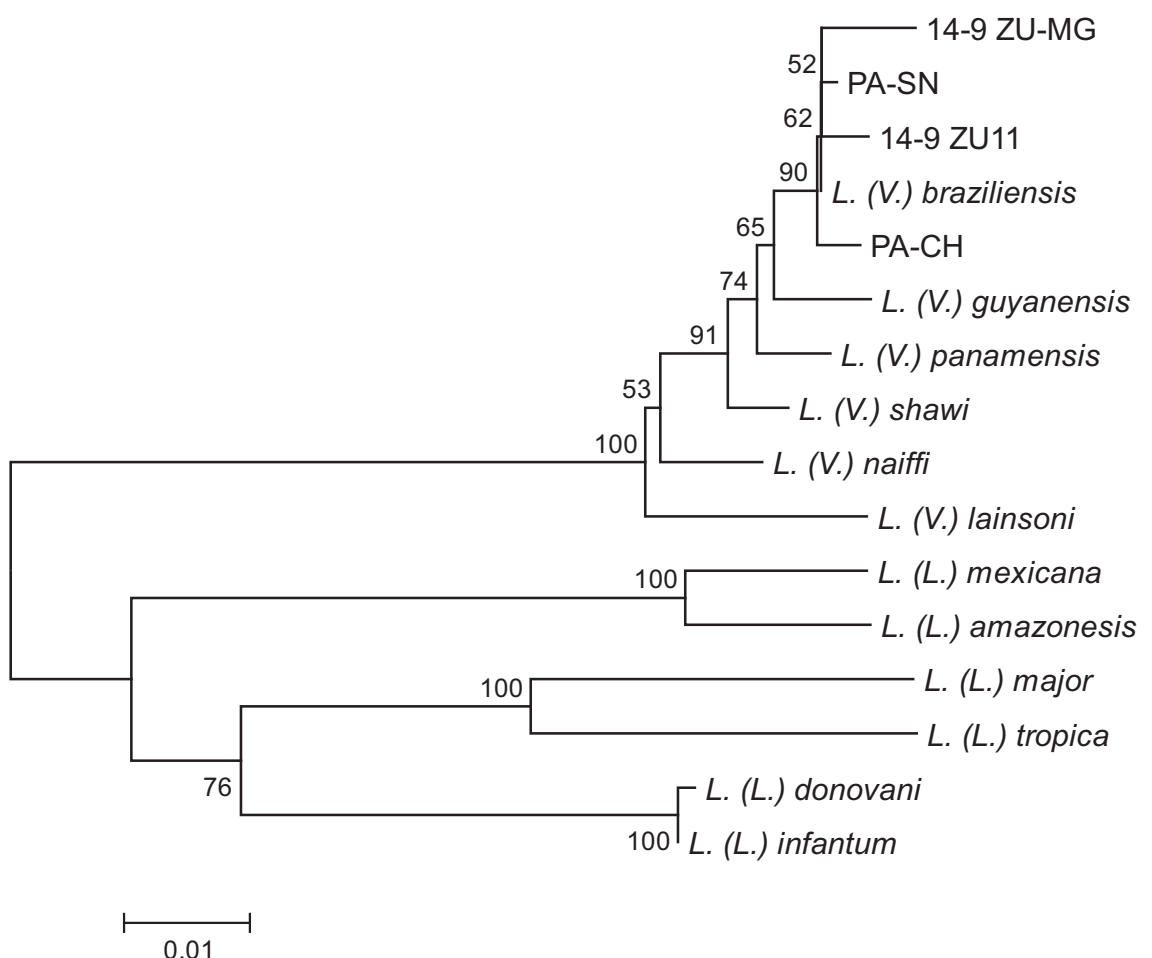

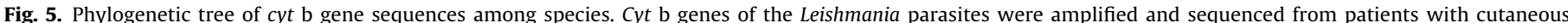

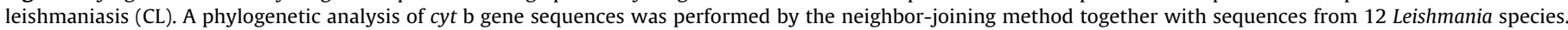

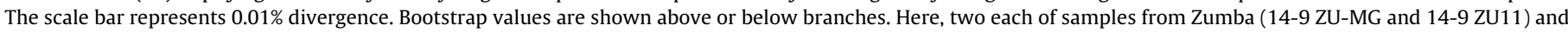
Palanda (PA-SN, and PA-CH: see Fig. 2) are depicted.

method is not so sensitive enough to detect all the positive leishmaniasis cases, showing a false negative result. The detection rate could therefore be enhanced if more sophisticated diagnostic tools, such as molecular and immunological techniques, are employed. However, no such a sophisticated diagnostic method is available in the present rural medical institutions. The aim/idea of the present study was to know the yearly and/or monthly fluctuation of registered smear-positive CL cases, in relation to the transmission-related factors, such as climatic, environmental and human behavioral changes in the study areas. In spite of such a longterm retrospective analysis, however, the numbers of reported cases are not enough for the precise analysis, especially because of a wide range (inter-country: Ecuador/Peru) of the insecticide spraying campaign using helicopter in the areas, which was conducted in 1993-1994 for the combat of dengue and leishmaniasis (Communication: epidemiologist H.R.O.). For this reason, only the data before the campaign was adopted for further detailed analysis.

In a revision of the registered $\mathrm{CL}$ cases in the two medical institutions, $57.9 \%$ of the total had occurred during six years from 1988 to 1993 . The precise reason for such a high number of reported cases in the period is not clear. Therefore, suffice it to say that it was caused by some ecological, climatic and human behavioral factors in the endemic regions, favoring increases in vector sand fly and reservoir animal populations. Furthermore, a marked migration of inhabitants was found during these years (especially before and after 1990) from mountainsides to the suburban area of the study sites (Plan de Desarrollo y Ordenamiento Territorial, Unidad de Gestion Territorial ZamoraChinchipe, http://www.zamora-chinchipe.gob.ec). Thereby the CL cases were notified more correctly at the present medical institutions. Thus, the change of life styles and activities of the inhabitants were discerned during the period. The high numbers of CL cases in 1988-1993 were followed by a marked decrease after the insecticide spraying campaign in 1993-1994, with a relatively low and irregular number. The deforestation around the housing and work-field areas, as seen in Fig. 3, might be contributing to such a low number of CL cases from 1994 through 2012. Deforestation rate was 13.3\% during 2000 and 2008 in the province (Unidad de Gestion Territorial Zamora-Chinchipe, http://www.zamora-chinchipe.gob.ec).

Monthly average numbers of reported CL cases in the study period from 1986 to 2012, revealed a higher occurrence of cases during March and August. In the present study, meteorological data (only precipitation) at the station M503-INAMHI are available from 1990 to 2011. Monthly numbers of reported cases $(45.1 \%$; $1047 / 2323$ of the total) from 1990 to 1993 were detected and used for the analysis in relation to the precipitation. As shown in Fig. 4, it has a tendency to show a higher average number of the occurrence of CL cases during March and August, the rainy season in the areas. A statistical significance was found between the monthly average number of CL cases and the monthly precipitation ( $p=0.01474)$. As with other vector-borne diseases such as malaria, vector sand fly density is correlated to seasonal patterns and also correlated with number of CL cases (Gomez and Hashiguchi, 1991; Feliciangeli and Rabinovich, 1998; Rabinovich and Feliciangeli, 2004; Chaves and Pascual, 2006).

Frank et al. (2002) studied the impact of the El Niño/Southern Oscillation on VL in Brazil, and pointed out that the rainy season is followed by an increase in vector density (around May there), which triggers a severe increase in infection rate in high-risk populations. During the present study period, "strong" El Niño occurred in 1987-1988 and 1997-1998, and "moderate" one, in 1986-1987, 1991-1992, 1994-1995, 2002-2003, and 2009-2010; a "strong" El Niño has not occurred since 1997-1998 to present (El Niño and La Niña Years and Intensities, Jan Null, CCM 07-Feb-2015). No 
clear-cut relationship between the "strong" or "moderate" El Niño and the reported CL cases was recognized, though higher numbers $(243-406 ; 38.4 \%$ of the total) of the cases were recorded in 1991-1993.

In the Ecuadorian CL endemic areas (Pedro Vicente Maldonado, Los Bancos and Puerto Quito, Pichincha province), the northwest Andean slope (cordillera), about $100-650 \mathrm{~m}$ a.s.l., a relatively high number of the clinical cases (2007-2011) was found in the period from October to January, the rainy season in the area, demonstrating $45.4 \%$ of the total cases (196/432); the lowest number in May, $2.8 \%$ of the total (Calvopiña et al., 2012). In the Andean CL endemic area, Paute, Azuay province, $2300-2500 \mathrm{~m}$ a.s.l., the sand fly population density and the natural infection with the Leishmania promastigote were examined throughout the year, and both the density and the infection revealed higher rates during the period from February to July, suggesting the transmission time of CL in the rainy season in the area (Gomez and Hashiguchi, 1991). In the current study, a higher number of monthly $\mathrm{CL}$ cases was recorded between March and August of almost all of the years during 1986-2012, the rainy seasons and the beginning of dry seasons in the present study areas. It is noticeable to mention that the time of transmission of leishmaniasis would depend on the rainy seasons at each geographic region of Ecuador, which has diverse climatic features at each geographic region. Such information would be important for future planning of control of the disease, leishmaniasis in the country. Naturally, other factors should be taken into consideration, especially on the different and diverse human activities such as environmental change/modification, urbanization, migration and settlement of non-immune populations, development of agro-industrial projects, road constructions, etc.

To know the circulating Leishmania species in the area, patient's lesion materials of FTA card and smears were analyzed by PCR, and identified as $L$. (V.) braziliensis. In this area, Le Pont et al. (1994) identified the parasites as intermediate form between $L$. $(V$.) panamensis and $L$. (V.) braziliensis by isoenzyme electrophoresis. We characterized the clinical isolates from El Chorro and La Chonta, Canton Chinchipe, Zamora-Chinchipe province, and identified $L$. $(V$.) braziliensis, by serodeme analysis using species-specific monoclonal antibodies (Furuya et al., 1997). This time, we also identified L. $(V$.$) braziliensis by PCR analysis of materials from FTA card and$ smear specimens from Zumba-Chinchipe and Palanda, ZamoraChinchipe. The species is most wide-spread and responsible for severe CL cases in the New World.

\section{Funding}

This study was financially supported by the Ministry of Education, Culture and Sports, Science and Technology (MEXT) of Japan (Grant Nos. 23256002 and 25257501), and the Prometeo Project of the Secretaría Nacional de Educación Superior, Ciencia, Tecnología e Innovación (SENESCYT), Ecuador.

\section{Conflict of interest}

The authors have no conflicts of interest to declare.

\section{Acknowledgements}

We are indebted to Dr. Ramón Calderon, director of Zumba hospital, Canton Chinchipe; Dr. Pablo Bejarano, director of Palanda health center, Canton Palanda; Ms. Martha Herrera, microscopist of SNEM, Zumba; Ms. Alexandra Villavicencio, microscopist of Palanda health center; and all the personnel who participated in the diagnosis, treatment and follow-up of patients during the present study, for their invaluable support.

\section{References}

Alvar, J., Velez, I.D., Bern, C., Herrero, M., Desjeux, P., Cano, J., Jannin, J., den Boer, M. WHO Leishmaniasis Control Team, 2012. Leishmaniasis worldwide and global estimates of its incidence. PLoS ONE 7, e35671.

Amunarriz, M.U., 1982. Leishmaniasis. In: Amunarriz, M.U (Ed.), Salud y enfermedad patologia tropical en la Region Amazonica. Edicion CICAME, Napo Ecuador, pp. $71-88$.

Armijos, R.X., Chico, M.E., Cruz, M.E., Guderian, R.H., Kreutzer, R.D., Bermall, J.D., Rogers, M.D., Grogl, M., 1990. Human cutaneous leishmaniasis in Ecuador: identification of parasites by enzyme electrophoresis. Am. J. Trop. Med. Hyg. 42, 424-428.

Calero, G.H., Coronel, V.V., 1981. Estudio de la leishmaniasis cutanea en una asentamiento agricola precordillerano. Anal. Med. Cirug. 4, 28-32.

Calvopiña, M., Armijos, R.X., Hashiguchi, Y., 2004. Epidemiology of leishmaniasis in Ecuador: current status of knowledge. Mem. Inst. Oswaldo Cruz 99, 663-672.

Calvopiña, M., Loor, R., Lara, F., Zambrano, P., Hashiguchi, Y., 2012. Prevalencia y formas clínicas de las leishmaniasis en el noroccidente de la provincia de Pichincha - Ecuador. Rev. Fac. Cienc. Med. (Quito) 37, 31-37.

Carrera, C.T., 1953. Anotaciones sobre la leishmaniasis selvatica americana e cutaneomucosa. Rev. Ecuat. Entomol. Parasitol. 1, 76-90.

Chaves, L.F., Pascual, M., 2006. Climate cycles and forecasts of cutaneous leishmaniasis, a nonstationary vector-borne disease. PLoS Med. 3, e298, http://dx.doi.org/10.1371/journal.pmed.0030295.

Desjeux, P., 2001. The increase in risk factors for leishmaniasis worldwide. Trans. R. Soc. Trop. Med. Hyg. 95, 239-243.

Feliciangeli, M.D., Rabinovich, J., 1998. Abundance of Lutzomyia ovallesi but no Lu. gomezi (Diptera: Psychodidae) correlated with cutaneous leishmaniasis incidence in north-central Venezuela. Med. Vet. Entomol. 12, 121-131.

Frank, C.R., Ziller, M., Staubach, C., Latif, M., 2002. Impact of the E Nino/Southern Oscillation on visceral leishmaniasis, Brazil. Emerg. Infect. Dis. 8 914-916.

Furuya, M., Akimaru, Y., Mimori, T., Shiraishi, M., Gomez, E.A.L., Nonaka, S., Hashiguchi, Y., 1997. Identification of species of Ecuadorian Leishmania isolates by ELISA using monoclonal antibodies. In: Hashiguchi, Y. (Ed.), Studies on New World Leishmaniasis and Its Transmission with Special Reference to Ecuador (Res. Rep. Ser. 5). Kyowa Printing \& Co. Ltd., Kochi, Japan, pp. 11-20.

Gomez, E.A.L., Hashiguchi, Y., 1991. Monthly variation in natural infection of the sandfly Lutzomyia ayacuchensis with Leishmania mexicana in an endemic focus in the Ecuadorian Andes. Ann. Trop. Med. Parasitol. 85, 407-411.

Gomez, E.A.L., Kato, H., Hashiguchi, Y., 2014a. Man-biting sand fly species and natural infection with the Leishmania promastigote in leishmaniasis-endemic areas of Ecuador. Acta Trop. 140, 41-49.

Gomez, E.A.L., Kato, H., Mimori, T., Hashiguchi, Y., 2014b. Distribution of Lutzomyia ayacuchensis, the vector of Andean-type cutaneous leishmaniasis, at different altitudes on the Andean slope of Ecuador. Acta Trop. 137, $118-122$.

Grimaldi Jr., G., Tesh, R.B., McMahon-Pratt, D., 1989. A review of the geographic distribution and leishmaniasis in the New World. Am. J. Trop. Med. Hyg. 41, 687-725.

Hashiguchi, Y., Coronel, V.V., Gomez, E.A.L., 1984. An epidemiological study of leishmaniasis in a plantation "Cooperativa 23 de Febrero" newly established in Ecuador. Jpn. J. Parasitol. 33, 393-401.

Hashiguchi, Y., Gomez, E.A.L., 1991. A review of leishmaniasis. Bull. Pan Am. Health Org. 25, 64-76.

Hashiguchi, Y., Gomez, E.A.L., Coronel, V.V., Mimori, T., Kawabata, M., Furuya, M., Nonaka, S., Takaoka, H., Alexander, J.B., Quizhpe, A.M., Grimaldi Jr., G., Kreutzer, R.D., Tesh, R.B., 1991. Andean leishmaniasis in Ecuador caused by infection with Leishmania mexicana and L. major-like parasites. Am. J. Trop. Med. Hyg. 44, 205-217.

Heinert, J.F., 1924. Un caso de leishmaniasis cutaneomucosa. Anal. Soc. Med. Quirurug. Guayas 3, 450-451.

Kato, H., Calvopina, M., Criollo, H., Hashiguchi, Y., 2013. First human cases of Leishmania (Viannia) naiffi infection in Ecuador and identification of its suspected vector species. Acta Trop. 128, 710-713.

Kato, H., Gomez, E.A.L., Yamamoto, Y., Calvopina, M., Guevara, A.G., Marco, J.D., Barroso, P.A., Iwata, H., Hashiguchi, Y., 2008. Natural infection of Lutzomyia tortura with Leishmania (Viannia) naiffi in an Amazonian area of Ecuador. Am. J. Trop. Med. Hyg. 79, 438-440.

Leon, L.A., 1951. Estudio y presentacion de un caso grave de leishmaniasis tegumentaria tratado con Repodral. Rev. Kuba Med. Trop. 7, 31-37.

Le Pont, F., Barrera, C., Caceres, A.G., Galati, E.A.B., Jarra, O., Riofrio, A.R., Mouchet J., Echeverria, R., Guderian, R.H., 1994. Leishmaniose en Equateur 6. Note epidemiologique et entomologique sur le foyer de leishmaniose de Zumba. Ann. Soc. Belge Med. Trop. 74, 43-49.

Mimori, T., Grimaldi Jr., G., Kreutzer, R.D., Gomez, E.A.L., McMahon-Pratt, D., Tesh, R.B., Hashiguchi, Y., 1989. Identification, using isoenzyme electrophoresis and monoclonal antibodies of Leishmania isolated from humans and wild animals of Ecuador. Am. J. Trop. Med. Hyg. 40, 154-158. 
Rabinovich, L.E., Feliciangeli, M.D., 2004. Parameters of Leishmania braziliensis transmission by indoor Lutzomyia ovallesi in Venezuela. Am. J. Trop. Med. Hyg. 70, 373-382.

Rodriguez, J.D.M., 1974. Genero Leishmania. In: Rodriguez, J.D.M (Ed.), Lecciones de Porasitologia humana. Departamento de Publicacion de Universidad de Guayaquil, Guayaquil, Ecuador, pp. 170-185.

Rodriguez, J.D.M., Aviles, F.N., 1953. Algunas observaciones sobre leishinaniasis cutaneomucosa en el Ecuador. Rev. Ecuat. Med. Trop. 10, 35-58.
Tamura, K., Peterson, D., Peterson, N., Stecher, G., Nei, M., Kumar, S., 2011. MEGAS: molecular evolutionary genetics analysis using maximum likelihood, evolutionary distance, and maximum parsimony methods. Mol. Biol. Evol. 28 2731-2739.

Thompson, J.D., Higgins, D.G., Gibson, T.J., 1994. CLUSTAL W: improving the sensitivity of progressive multiple sequence alignment through sequence weighting, position-specific gap penalties and weight matrix choice. Nucleic Acids Res. 22, 4673-4680. 